Poh-San Lai • Yasuhiro Takeshima • Kayo Adachi

Khanh van Tran • Hoan Thi Nguyen • Poh-Sim Low

Masafumi Matsuo

\title{
Comparative study on deletions of the dystrophin gene in three Asian populations
}

Received: May 20, 2002 / Accepted: July 1, 2002

\begin{abstract}
The frequency and distribution of deletions of 19 deletion-prone exons clustered in two hot spots in the proximal and central regions of the dystrophin gene were compared in three populations from Singaporean, Japan, and Vietnam. DNA samples obtained from 105 Singaporean, 86 Japanese, and 34 Vietnamese Duchenne muscular dystrophy patients were examined by polymerase chain reaction amplification. Deletions of the examined exons were found in $51.2 \%$ of Japanese patients but in $40.0 \%$ or less of the Singaporeans and Vietnamese. About two thirds of the deletions were localized in the central region and the remaining deletions were clustered at the proximal region. The most commonly deleted exons at the central deletion hot spot were exon 50 in the Singaporean, exons 49 and 50 in the Japanese, and exon 51 in the Vietnamese population. At the proximal deletion hot spot, the most commonly deleted exons were exons 6 and 8 in the Singaporeans, exons 12 and 17 in the Japanese, and exons 8 and 12 in the Vietnamese. Two cases each from Singapore and Japan had large-scale gross mutations spanning both deletion hot spots. Our results suggest that, although the presence and frequency of the two deletion hot spots may be similar in the three Asian populations analyzed, the distribution and frequency of deletions among the different exons can vary
\end{abstract}

P.-S. Lai · P.-S. Low

Division of Human Genetics, Department of Paediatrics, National

University of Singapore, Singapore

Y. Takeshima

Department of Pediatrics, Kobe University Graduate School of Medicine, Kobe, Japan

K. Adachi $\cdot$ K. van Tran $\cdot$ M. Matsuo

Division of Moleculan Modicine, Kobe University Graduate School of Medicine, Kobe, Japan

H. Thi Nguyen

Department of Endocrinology, Metabolism and Genetics, National Institute of Pediatrics, Hanoi, Vietnam

M. Matsuo $(\square)$

Division of Molecular Medicine, Kobe University Graduate School of Medicine, 7-5-1 Kusunoki-cho, Chuo-ku, Kobe 650-0017, Japan

Tel. +81-78-382-5700; Fax +81-78-382-5719

e-mail: matsuo@kobe-u.ac.jp as a result of population-specific intronic sequences that predispose individuals to preferential deletion breakpoints.

Key words Duchenne muscular dystrophy · Dystrophin gene - Deletion frequencies . Asian populations . Singaporean $\cdot$ Japanese $\cdot$ Vietnamese

\section{Introduction}

Duchenne muscular dystrophy (DMD) and Becker muscular dystrophy (BMD) are allelic disorders that cause progressive muscle atrophy. They are caused by defects in the dystrophin gene that is located on chromosome $\mathrm{X}$ at $\mathrm{p} 21$. Dystrophin is considered to be a major component of the subsarcolemmal cytoskeleton and has four distinct domains: an N-terminal actin binding domain, a large rodlike domain of 24 spectrin-like repeats, a cysteine-rich domain, and a C-terminal domain (Ahn and Kunkel 1993). The 3.0-Mb dystrophin gene is the largest known human gene with a total coding sequence of $11,220 \mathrm{bp}$ transcribed from 79 exons. Generally, about $60 \%$ of all DMD and BMD cases are due to gross gene deletions, $5 \%$ to duplications, and the remaining $35 \%$ to point mutations (Baumbach et al. 1989; Gillard et al. 1989). Frame-shift mutations that disrupt the translational reading frame lead to a truncated nonfunctional dystrophin protein that results in severe DMD, whereas mutations that maintain the reading frame result in a semifunctional protein that causes the milder BMD phenotype (Monaco et al. 1988).

Gross gene deletions are the most common mutation in the dystrophin gene. Southern hybridization with cDNA probes was initially used to analyze deletion/duplication mutations (Koenig et al. 1987; Baumbach et al. 1989). This allowed analysis of the entire coding region of the gene, and two deletion hot spots were localized to the proximal region of the gene extending from exons 1 to 19 , and to the central region extending from exons 44 to 60 (Koenig et al. 1987; Forrest et al. 1988). Because Southern hybridization was a laborious and time-consuming technique requiring the use 
of radioisotopes, a multiplex polymerase chain reaction (PCR) analysis that allowed the simultaneous coamplification of exons within the deletion hot spots was developed. Currently, exons 1 (or muscle promoter), 3, 4, 6, 8, 12, 13, $17,19,43,44,45,47,48,49,50,51,52$, and 60 have been screened for deletions by two PCR reactions (Chamberlain et al. 1988; Beggs et al. 1990). The use of the original multiplex sets would still give a combined detection rate of more than $98 \%$ of all deletion mutations of the dystrophin gene.

The frequency and pattern of intragenic deletions of the dystrophin gene have been reported in a number of populations (Hoffman and Kunkel 1989; Niemann-Seyde et al. 1992; Ballo et al. 1994; Kitoh et al. 1994; Dincer et al. 1996; Yuge et al. 1999; Werneck et al. 2001). Although some reports have concluded that there may not be ethnic differences in deletions of the dystrophin gene in populations, there have been studies suggesting the presence of population differences in the location of preferential deletion breakpoints in the dystrophin gene (Ballo et al. 1994; Herczegfalvi et al. 1999). Most of these previous deletion screening studies have been based on Caucasian populations with only a few Asian populations having been investigated (Mutirangura et al. 1995; Banerjee and Verma 1997; Ikezawa et al. 1998; Yuge et al. 1999). In this study, dystrophin gene deletions in DMD patients from three Asian populations, namely, Singaporean, Japanese, and Vietnamese were analyzed and a comparative analysis was carried out. The presence of different deletion patterns among the three populations is shown in this study, suggesting genetic difference in the three Asian populations.

\section{Patients and methods}

\section{Patients}

A total of 105 Singaporean Chinese patients, 86 Japanese, and 34 Vietnamese patients were recruited for this study with informed consent. All patients were diagnosed as having DMD on the basis of the clinical course, including muscle weakness, high evaluation of serum creatine kinase enzyme levels, histological findings of muscle biopsy specimens, electromyography, and known family histories.

\section{Deletion screening by multiplex PCR analysis}

Genomic DNA was isolated from peripheral blood leukocytes using the Wizard Genomic DNA purification kit (Promega Biotech, Madison, WI, USA). Multiplex PCR was performed using previously described pairs of primers: 1, 4, 8, 12, 13, 17, 19, 43, 44, 45, 48, 50, 51, 52 (Chamberlain et al. 1988), exons 3, 6, 47, 49, 60 (Beggs et al. 1990). Amplification was carried out in a total volume of $25 \mu \mathrm{l}$ containing $100 \mathrm{ng}$ of genomic DNA, $10 \mathrm{mM}$ Tris- $\mathrm{HCl}(\mathrm{pH} 8.3), 50 \mathrm{mM}$ $\mathrm{KCl}, 5 \mathrm{mM} \mathrm{NH}_{4} \mathrm{Cl}, 250 \mathrm{mM}$ of deoxyribonucleoside triphosphates (Promega Biotech), $1.5 \mathrm{mM} \mathrm{MgCl}_{2}, 6.25 \mathrm{pmol}$ of each primer, and 2 units of Taq polymerase (Perkin ElmerCetus, Norwalk CT, USA). PCR cycling conditions were
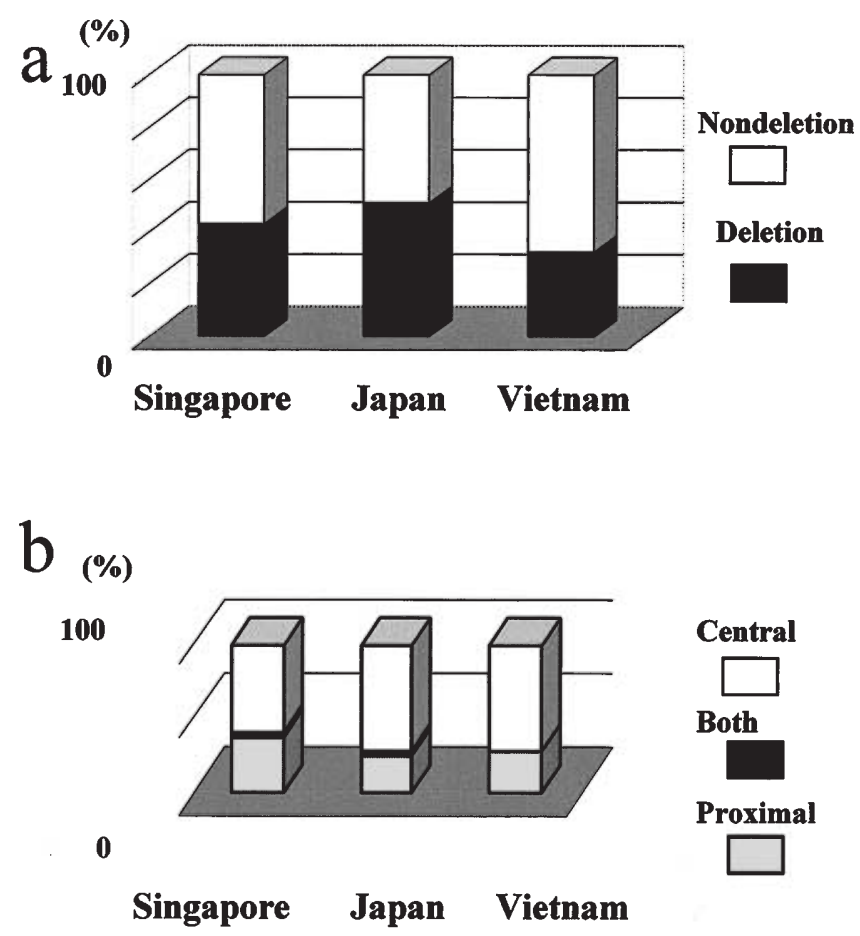

Fig. 1a,b. Summary of deletion screening of 19 deletion-prone exons. a Frequencies of deletions identified in three populations. b Distribution of deletions among the dystrophin gene in three populations

as follows: an initial denaturation at $95^{\circ} \mathrm{C}$ for $7 \mathrm{~min}$ followed by 30 cycles of denaturation at $94^{\circ} \mathrm{C}$ for $30 \mathrm{~s}$, annealing at $55^{\circ}-62^{\circ} \mathrm{C}$ for $50 \mathrm{~s}$, and extension at $72^{\circ} \mathrm{C}$ for $50 \mathrm{~s}$, and a final extension at $72^{\circ} \mathrm{C}$ for $5 \mathrm{~min}$. The PCR products were resolved by electrophoresis in a $2 \%$ agarose gel containing $0.5 \mu \mathrm{g} / \mathrm{ml}$ of ethidium bromide. All samples were analyzed in two separate reactions. Positive and negative controls were included using a normal genomic DNA sample and a blank buffer, respectively.

\section{Results and discussion}

The screening of 19 deletion-prone exons of the dystrophin gene in 105 Singaporean, 86 Japanese, and 34 Vietnamese patients showed deletions in $42(40.0 \%), 44(51.2 \%)$, and 11 $(32.4 \%)$ patients, respectively (Fig. 1). The frequency of deletions among the three populations did not differ significantly $(P=0.15)$. The majority of the deletions occurred in the central deletion hot spot in all three populations: 26 $(61.9 \%)$ in the Singaporeans, 31 (70.5\%) in the Japanese, and $8(72.7 \%)$ in the Vietnamese as compared with the proximal hot spot $(25.0 \%-33.3 \%)$ (Fig. 2). Two cases each in the Singaporean $(4.8 \%)$ and Japanese $(4.5 \%)$ populations were observed to have gross deletions spanning both hot spots from the proximal to central regions of the gene, but no such case was found in the Vietnamese population.

The most commonly deleted exons were exon 50 in the Singaporean (16 cases), exons 49 and 50 in the Japanese (22 


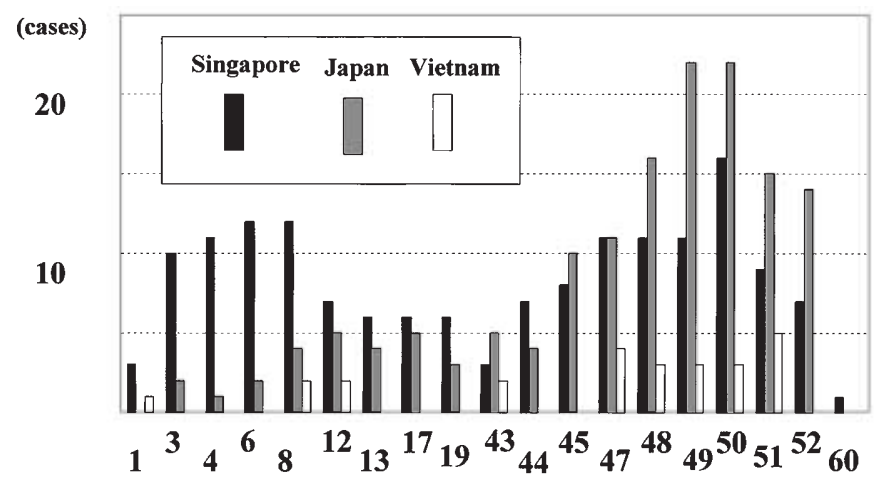

Exon number

Fig. 2. Distribution of deletions among 19 exons for three populations

cases), and exon 51 in the Vietnamese population (5 cases), as shown in Fig. 2. The distributions of the frequently deleted exons in the central hot spot were quite similar in all three populations. At the proximal hot spot, the most commonly deleted exons were clustered at exons 6 and 8 in the Singaporeans (12 cases), exons 12 and 17 in the Japanese ( 5 cases), and exons 8 and 12 in the Vietnamese ( 2 cases) (Fig. 2). These patterns suggest that a different molecular background in populations can produce different deletion mutations as a result of population-specific intronic sequences that predispose individuals to preferential deletion breakpoints.

Previous studies based on multiplex PCR analysis of the 19 deletion-prone exons have shown deletion frequencies ranging from $42 \%$ to $60 \%$ in various populations such as German, Italian, Polish, Turkish, and Indian (Covone et al. 1991; Niemann-Seyde et al. 1992; Dincer et al. 1996; Banerjee and Verma 1997; Lisiecka et al. 1998). Vietnamese patients showed the lowest deletion rate $(32.4 \%)$. This may be due to a high deletion rate in exons outside of the 19 deletion-prone exons. Further study is needed to clarify this observation.

In most of the studies, about one third of the deletions clustered at the proximal hot spot, with the remainder located at the central hot spot. The only exception to this pattern was a report in a Filipino population in which the majority of deletions occurred more frequently at the proximal hot spot $(80 \%)$ than at the central hot spot $(20 \%)$, but this anomaly could be due to the small sample size (Cutiongco et al. 1995). Thus, the three populations in this study do not differ significantly from populations reported in the literature, although the deletion frequencies appeared to be slightly lower in the Singaporeans and the Vietnamese. Because the occurrence of the two hot spot clusters is similar in almost all populations, it can be concluded that there is a general conservation of gross rearrangements of gene sequences in the two main regions of the dystrophin gene corresponding to the proximal and central deletion hot spots. However, the gene sequence is probably more conserved in the central deletion hot spot than it is in the proximal hot spot because a difference in the extent of deletion of exons was observed in the latter in the three populations in this study.

Our study showed that deletion frequencies in DMD populations from Singapore and Vietnam are similar but lower than in the Japanese population or other reported populations screened using the same multiplex PCR set of 19 deletion-prone exons (Ikezawa et al. 1998; Yuge et al. 1999; Werneck et al. 2001). Future studies covering exons not included in the multiplex set may yield a more accurate estimate of the actual deletion frequencies of the dystrophin gene in both Singaporean and Vietnamese populations (Baumbach et al. 1989; Koenig et al. 1989), especially if deletions occur more frequently than expected in exons outside the two hot spot regions. The strategy for deletion screening by multiplex PCR should take into account the deletion patterns and characteristics of each population. To save cost and time, investigators carrying out such an analysis need not screen for every exon in the initial investigation, so that nondeleted cases are then subsequently screened using additional exons before screening for point mutations. Our results show that subtle population differences can exist in deletion patterns of exons in the dystrophin gene, and populations should be screened first before adopting the multiplex PCR deletion screening strategy for rapid diagnosis.

Acknowledgments This study was supported in part by grants from the National Medical Research Council of Singapore and the National University of Singapore (RP 3910424 and RP 3960343), and from the Ministry of Education, Science and Culture of Japan. P.-S.L. and M.M. were also recipients of JSPS exchange fellowships that facilitated collaborative studies in the area of DMD/BMD.

\section{References}

Ahn AH, Kunkel LM (1993) The structural and functional diversity of dystrophin. Nat Genet 3:283-291

Ballo R, Viljoen D, Beighton P (1994) Duchenne and Becker muscular dystrophy prevalence in South Africa and molecular findings in 128 persons affected. S Afr Med J 84:494-497

Banerjee M, Verma IC (1997) Are there ethnic differences in deletions in the dystrophin gene? Am J Med Genet 68:152-157

Baumbach LL, Chamberlain JS, Ward PA, Farwell NJ, Caskey CT (1989) Molecular and clinical correlations of deletions leading to Duchenne and Becker muscular dystrophies. Neurology 39:465-474

Beggs AH, Koenig M, Boyce FM, Kunkel LM (1990) Detection of $98 \%$ of DMD/BMD gene deletions by polymerase chain reaction. Hum Genet 86:45-48

Chamberlain JS, Gibbs RA, Ranier JE, Nguyen PN, Caskey CT (1988) Deletion screening of the Duchenne muscular dystrophy locus via multiplex DNA amplification. Nucleic Acids Res 16:11141-11156

Covone AE, Lerone ML, Romeo G (1991) Genotype-phenotype correlation and germline mosaicism in DMD/BMD patients with deletions of the dystrophin gene. Hum Genet 87:353-360

Cutiongco EM, Padilla CD, Takenaka K, Yamasaki Y, Nishio H, Matsuo M (1995) More deletions in the 5' region than in the central region of the dystrophin gene were identified among Filipino Duchenne and Becker muscular dystrophy patients. Am J Med Genet 59:266-267

Dincer P, Topaloglu H, Ayter S, Ozguc M, Tasdemir HA, Renda Y (1996) Molecular deletion patterns in Turkish Duchenne and Becker muscular dystrophy patients. Brain Dev 18:91-94

Forrest SM, Cross GS, Flint T, Speer A, Robson KJH, Davies KE (1988) Further studies of gene deletions that cause Duchenne and Becker muscular dystrophies. Genomics 2:109-114 
Gillard EF, Chamberlain JS, Murphy EG, Duff CL, Smith B, Burghes AH, Thompson MW, Sutherland J, Oss I, Bodrug SE, Klamut HJ, Ray PN, Worton RG (1989) Molecular and phenotypic analysis of patients with deletions within the deletion-rich region of the Duchenne muscular dystrophy $(D M D)$ gene. Am J Hum Genet 45:507-520

Herczegfalvi A, Toth G, Gyurus P, Morava E, Endreffy E, Fodor F, Mechler F, Laszlo A, Rasko I, Melegh B (1999) Deletion patterns of dystrophin gene in Hungarian patients with Duchenne/Becker muscular dystrophies. Neuromuscul Disord 9:552-554

Hoffman EP, Kunkel LM (1989) Dystrophin abnormalities in Duchenne/Becker muscular dystrophy. Neuron 2:1019-1029

Ikezawa M, Minami N, Takahashi M, Goto Y, Miike T, Nonaka I (1998) Dystrophin gene analysis on 130 patients with Duchenne muscular dystrophy with a special reference to muscle mRNA analysis. Brain Dev 20:165-168

Kitoh Y, Matsuo M, Nishio H, Nakamura H (1994) Amplification of selected exons by polymerase chain reaction enables determination of the translational reading frame of dystrophin mRNA. Kobe J Med Sci 40:39-48

Koenig M, Hoffman EP, Bertelson CJ, Monaco AP, Feener C, Kunkel LM (1987) Complete cloning of the Duchenne muscular dystrophy (DMD) cDNA and preliminary genomic organization of the DMD gene in normal and affected individuals. Cell 50:509-517

Koenig M, Beggs AH, Moyer M, Scherpf S, Heindrich K, Bettecken T, Meng G, Muller CR, Lindlof M, Kaariainen H, de la Chapelle A, Kiuru A, Savontaus M-L, Gilgenkrantz H, Recan D, Chelly J, Kaplan J-C, Covone AE, Archidiacono N, Romeo G, Liechti-Gallati S, Schneider V, Braga S, Moser H, Darras BT, Murphy P, Francke
U, Chen JD, Morgan G, Denton M, Greenberg CR, Wrogemann K, Blonden LAJ, van Paassen HMB, van Ommen GJB, Kunkel LM (1989) The molecular basis for Duchenne versus Becker muscular dystrophy: correlation of severity with type of deletion. Am J Hum Genet 45:498-506

Lisiecka D, Wigowska-Sowinska J, Kwiatkowska J, GalasZgorzalewicz B, Slomski R (1998) Molecular-genetic characteristics of mutations in dystrophin gene and clinical symptoms in Duchenne muscular dystrophy. Neurol Neurochir Pol 32:1069-1079

Monaco AP, Bertelson CJ, Liechti-Gallati S, Moser H, Kunkel LM (1988) An explanation for the phenotypic differences between patients bearing partial deletions of the DMD locus. Genomics 2:9095

Mutirangura A, Jongpiputvanich S, Norapucsunton T, Theamboonlers A, Srivuthana S, Promchainant C, Tumwasorn S, Sueblinvong T (1995) Multiplex PCR to detect the dystrophin gene deletion in Thai patients. J Med Assoc Thai 78:460-465

Niemann-Seyde S, Slomski R, Rininsland F, Ellermeyer U, Kwiatkowska J, Reiss J (1992) Molecular genetic analysis of 67 patients with Duchenne/Becker muscular dystrophy. Hum. Genet. 90:65-70

Werneck LC, Scola RH, Maegawa GH, Werneck MC (2001) Comparative analysis of PCR-deletion detection and immunohistochemistry in Brazilian Duchenne and Becker muscular dystrophy patients. Am J Med Genet 103:115-120

Yuge L, Hui L, Bingdi X (1999) Detection of gene deletions in Chinese patients with Duchenne/Becker muscular dystrophy using cDNA probes and the polymerase chain reaction method. Life Sci 65:863869 